\title{
AC Tie-Line Power Oscillation Mechanism and Peak Value Calculation for a Two-Area AC/DC Parallel Interconnected Power System Caused by LCC-HVDC Commutation Failures
}

\author{
Li Sun ${ }^{1,2}$, Hongbo Liu ${ }^{2}$ and Chenglian Ma ${ }^{2, *}$ \\ 1 School of Electrical and Electronic Engineering, North China Electric Power University, \\ Beijing 102206, China; sunli@neepu.edu.cn \\ 2 Key Laboratory of Modern Power System Simulation and Control \& Renewable Energy Technology, \\ Ministry of Education, Northeast Electric Power University, Jilin 132012, China; liuhongbo@neepu.edu.cn \\ * Correspondence: machenglian@neepu.edu.cn; Tel.: +86-135-1432-0646
}

Received: 1 January 2020; Accepted: 5 March 2020; Published: 6 March 2020

check for updates

\begin{abstract}
With the rapid development of ultra-high-voltage (UHV) AC/DC, especially the step-by-step upgrading of the UHV DC transmission scale, security presents new challenges. Commutation failure (CF) is a common fault in line commutated converter (LCC) high-voltage direct current (HVDC) power systems. Once failure happens, it may cause power oscillations in a system. In this paper, taking a two-area AC/DC parallel interconnected power system as the example, based on the impulse response model of second-order linear system, the mechanism of power oscillation on the AC tie-line caused by CF are clarified. It is proved that the peak value of the AC tie-line power oscillation is mainly determined by the DC power and the equivalent CF duration, the frequency and damping ratio of dominant area oscillation mode. Meanwhile, the peak time is mainly determined by the oscillation frequency. Finally, the correctness and effectiveness of the algorithms are verified by a simulation analysis of an extended IEEE-39-bus AC/DC parallel interconnected power system. These research results can provide a basis for the arrangement of the operating modes and the formulation of control measures for interconnected power grids.
\end{abstract}

Keywords: high-voltage direct current (HVDC); commutation failure; impulse response; tie-line; power oscillation

\section{Introduction}

Since the 1980s, with the rapid progress in high-power electronic devices and computer control technology, HVDC technology has made considerable progress. The primary energy and load distribution are reversed in China (Figure 1). To meet the urgent needs of clean energy delivery, load center power supply, energy saving and emission reduction, the State Grid vigorously develops ultrahigh voltage (UHV) AC and DC technologies suitable for long-distance and large capacity transmission [1]. One type of HVDC transmission that has been widely used in China's State Grid nowadays is line commutated converter (LCC) HVDC. There are total of 20 HVDC lines that are based on LCC technologies. The majority of these lines are rated at $\pm 800 \mathrm{kV}$, except two that are at $\pm 500 \mathrm{kV}$ and one (from Changji, Xinjiang to Xuancheng, Anhui, under development) at $\pm 1100 \mathrm{kV}$. Almost all lines that are currently in operation were developed after 2010 [2]. If an LCC-HVDC system with a large capacity fails, it would have a large impact on the sending and receiving terminals and could even affect the stability of the power grid, thus resulting in cascading failures [3]. 


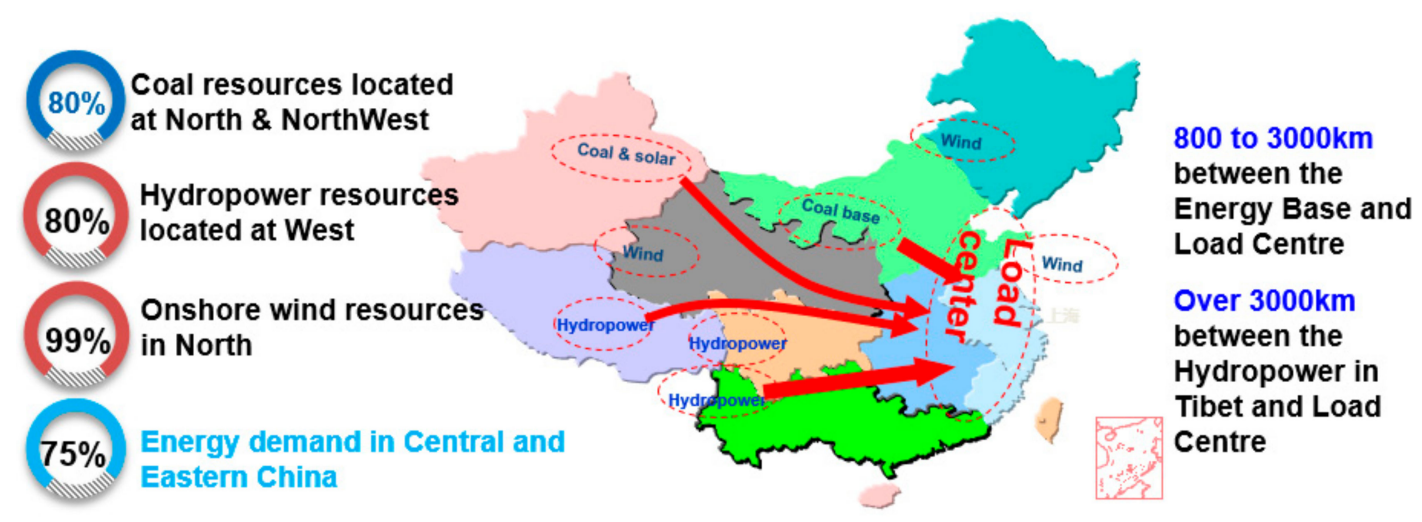

Figure 1. Primary energy and load distribution in China.

Currently, China is in a transitional period of conversion to a UHV power grid. With the rapid development of UHV AC/DC, especially the step-by-step upgrading of the UHV DC transmission scale, the following substantial changes had taken place in the operating characteristics of power grids $[4,5]$ : the coupling of $A C$ and DC, in which the sending and receiving ends became closer and the influences of faults on the power grids extend from local to global; the contradiction of 'strong DC and weak $\mathrm{AC}^{\prime}$ had become a persistent problem; grid frequency and voltage stability problems had become increasingly prominent for the mass generation of renewable power and DC transmission [6]. Security also presented new challenges [7,8]. For hybrid UHV AC/DC power systems in China, which are in the initial stage of UHV power grid construction, the transmission structures at both ends of the system are usually growing and weakly connected; thus, the static power angle stability limits of these systems are relatively low. As the proportion of DC transmission capacity increased, once an event of power disturbance occurred, a large AC tie-line power oscillation would be occurred, which required that the AC tie-line must withstand the sharply increasing pressure [9]. If a power burst exceeded the static reserve capacity, the AC tie-line may experience instability. In this case, the sending and receiving end were completely disconnected: there would be a major surplus of power at the sending end, and there would be a major shortage of power at the receiving end. In this case, the whole system may crash [10].

In the face of these problems, guaranteeing the security and stability of a power system is valuable. A HVDC grid comprehensive test model had been designed based on the distribution of China's renewable energy, its existing features and the future development trends [11,12]. In the theoretical analysis of the relationship between static voltage stability and the grid strength of multi-infeed LCC-HVDC (MIDC) systems, a generalized short-circuit ratio (gSCR) resolved the ambiguity encountered by the earlier indices arising from empirical reasoning [13,14]. A unified model consisting of a multivariable feedback control system (FCS) had studied the dynamics of power systems with HVDC transmission links in [15]. To enhance the stability of the large-scale integration of wind, solar and marine-current power generation, a PID damping controller and an adaptive-network-based fuzzy inference system (ANFIS) had been proposed to achieve damping improvement [16]. To stabilize and enhance the dynamic performance of a large AC system that was segmented by LCC-HVDC links, a global supplementary control strategy (GSC) based on a linear quadratic Gaussian method was investigated in [17]. It is a very important task to study the stability of hybrid UHV AC/DC power system.

In recent years, LCC-HVDC transmission has been widely used in the project of 'west to east transmission,' 'north and south mutual supply' and 'national networking' in China [18]. Due to the use of semi-controlled thyristor devices as commutation elements, the HVDC transmission process depends on the power supply provided by the AC system. All the factors that cause the change of the voltage of the system (such as distortion, zero-point migration etc.) may cause commutation failure (CF) of the inverter [19]. In East China, CFs happened more than 20 times due to AC fault from January to September 2017 [20]. In a multi-infeed HVDC transmission system, a fault of the 
receiving AC system may cause simultaneous or successive commutation failures that may lead to the blocking of the HVDC system in serious cases. The interruption of the transmission of DC power ultimately threatened the safe and stable operation of the whole system [21]. CF was an adverse dynamic event in which the commutator was supposed to turn off but continued to conduct electricity without transferring its current to the next valve in the firing sequence [22]. Most CFs are caused by a voltage reduction due to AC system faults. CFs could be detrimental to HVDC links [23]. Once continuous CFs occur, they could result in significant direct current increases and thus lead to an overheating of converter valves that would shorten their lifespans [24,25]. To reduce the probability of a CF occurring, many papers have focused on improving algorithms [26-28], improving the DC control strategy [29-31] and adjusting the network topology [32]. A hybrid configuration had been proposed that inserted a dynamic series capacitor and added fixed parallel capacitors at the valve side of the converter transformer [33-35]. Another strategy involving an enhanced LCC (E-LCC) with embedded fully controlled submodules had been proposed [36], which had stronger CF immunity and a better recovery performance than a capacitor commutated converter (CCC). In addition, unlike a CCC, an E-LCC would not bring an additional voltage stress on the converter valves. A new control concept was proposed that always offered an inherent current limitation for three-phase grid-tied droop-controlled inverters [37]. An electromagnetic transient model of an LCC-HVDC system with a synchronous condenser was developed that could effectively suppress commutation failures [38].

Although many papers have mentioned different methods to reduce the probability of CFs, and even eliminate $\mathrm{CFs}$ under some fault cases, $\mathrm{CFs}$ are unavoidable in existing projects. It may affect the stability of the whole AC/DC hybrid system. Therefore, analyzing the power fluctuation mechanism and peak value calculation of large area AC tie-lines under the impact of DC CFs are urgently needed. The appropriate calculation method for peak value is mainly based on the causes. This method uses a layout-aware power grid to detect high power patterns. A method had also been proposed to estimate the peak value of lightning induced voltages in an infinite line [39,40]. A method of layout-aware weighted switching activity identification flow has been proposed that evaluates the peak power on power bumps to detect high power patterns [41]. A fast approach to calculate the power oscillation peak value on an AC tie-line after HVDC commutation failure was proposed in [42].

The main contributions of the paper can be summarized as follows: taking a two-area AC/DC parallel interconnected power system as the example, based on the impulse response model of second-order linear system, the mechanism of power oscillation on the AC tie-line caused by CF was clarified. It was proved that the peak value of the AC tie-line power oscillation is mainly determined by the DC power and the equivalent $\mathrm{CF}$ duration, the frequency and damping ratio of the dominant area oscillation mode. Meanwhile, the peak time is mainly determined by the oscillation frequency. Finally, the correctness and effectiveness of the algorithms are verified by a simulation analysis of an extended IEEE-39-bus AC/DC parallel interconnected power system. These research results can provide a basis for the arrangement of the operating modes and the formulation of control measures for interconnected power grids. The remaining parts of this paper are organized as follows: in Section 2, a linearized model of an AC tie-line power impulse in a two-area AC/DC parallel interconnected power system is built. In Section 3, the power fluctuations in this AC system caused by DC faults are analyzed. Simulations are implemented for an extended IEEE-39-bus AC/DC parallel interconnected power system with the aid of the proposed results in Section 4. Concluding remarks are given in Section 5.

\section{Linearized Model of AC Tie-Line Power Impulses in an AC/DC Parallel Interconnected Power System}

The two-area AC/DC parallel interconnected power system equivalent model is shown in Figure 2. A CF may occur when a disturbance or fault occurs in the receiving AC system. During the CF, large power drops or interrupts occur instantaneously, and a large amount of instantaneous power surplus appear in the sending end system that may cause a serious impact on the AC tie-line. 


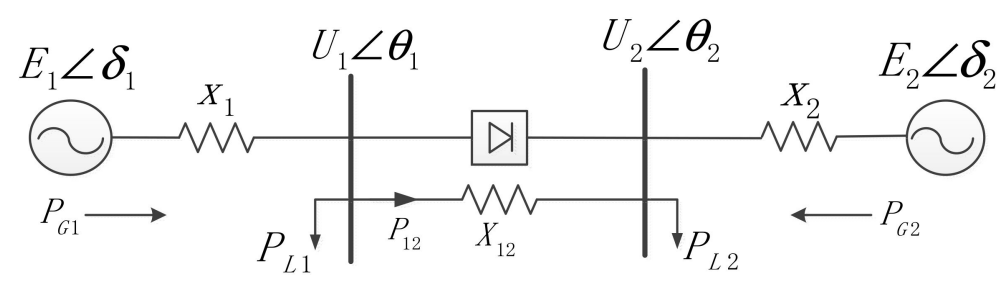

Figure 2. The two-area AC/DC parallel interconnected power system equivalent model.

According to Figure 2, the rotor equation of the equivalent generators can be obtained [43]:

$$
\left\{\begin{array}{l}
M_{1} \frac{d \delta_{1}^{2}}{d t^{2}}=P_{G 1}-P_{D 12}-P_{L 1}-P_{12} \\
M_{2} \frac{d \delta_{2}^{2}}{d t^{2}}=P_{G 2}+P_{D 12}-P_{L 2}+P_{12}
\end{array}\right.
$$

where $P_{12}=\frac{U_{1} U_{2}}{x_{12}} \sin \left(\theta_{1}-\theta_{2}\right)$.

To conduct a quantitative analysis, the two-machine rotor motion in Equation (1) should be converted to a single-machine form. If the reactance of the AC tie-line is much larger than that of the equivalent generator and the interconnection of areas 1 and 2 are weak, then $x_{12} \gg x_{1}$ and $x_{2}$; then, the approximation can be perform that $\delta_{1} \approx \theta_{1}$ and $\delta_{2} \approx \theta_{2}$. The single-machine rotor motion equation is shown in (2):

$$
\frac{d^{2} \delta_{12}}{d t^{2}}=\frac{P_{G 1}-P_{L 1}}{M_{1}}-\frac{P_{G 2}-P_{L 2}}{M_{2}}-\left(\frac{1}{M_{1}}+\frac{1}{M_{2}}\right) \frac{U_{1} U_{2}}{x_{12}} \sin \left(\delta_{1}-\delta_{2}\right)-\left(\frac{1}{M_{1}}+\frac{1}{M_{2}}\right) P_{D C}
$$

For simplification purposes, the impact of the generator mechanical power and load power variations are not considered here. Thus, Equation (2) can be restated as (3):

$$
\frac{d^{2} \delta_{12}}{d t^{2}}=P_{T}^{\prime}-\left(P_{12}^{\prime}+P_{D C}^{\prime}\right)
$$

The equivalent generator power can be obtained as:

$$
P_{T}^{\prime}=\frac{P_{G 1}-P_{L 1}}{M_{1}}-\frac{P_{G 2}-P_{L 2}}{M_{2}}
$$

The equivalent DC transmission power can be obtained as:

$$
P_{D C}^{\prime}=\left(\frac{1}{M_{1}}+\frac{1}{M_{2}}\right) P_{D C}
$$

The equivalent electromagnetic power can be obtained as:

$$
P_{12}^{\prime}=\left(\frac{1}{M_{1}}+\frac{1}{M_{2}}\right) \frac{U_{1} U_{2}}{x_{12}} \sin \delta_{12}
$$

It is assumed that the mechanical power of the generator and system load remain constant during the disturbance period of the system; thus, Equation (3) is linearized at the equilibrium point:

$$
\begin{gathered}
\Delta \frac{d \delta_{12}^{2}}{d t^{2}}=-\Delta P_{D C}^{\prime}-\Delta P_{E}^{\prime} \\
\Delta P_{E}^{\prime}=\left(\frac{1}{M_{1}}+\frac{1}{M_{2}}\right) \frac{U_{1} U_{2}}{x_{12}} \cos \delta_{120} \Delta \delta_{12}
\end{gathered}
$$


where, by letting $K_{s}=\frac{U_{1} U_{2}}{x_{12}} \cos \delta_{120}$ be the synchronous torque coefficient and $\frac{1}{M}=\frac{1}{M_{1}}+\frac{1}{M_{2}}$, Equation (7) can be restated as (9):

$$
M \Delta \frac{d \delta_{12}^{2}}{d t^{2}}+K_{S} \Delta \delta_{12}=-\Delta P_{D C}
$$

When the damping effect of the system is considered, Equation (9) can be restated as follows:

$$
M \Delta \frac{d \delta_{12}^{2}}{d t^{2}}+D \Delta \frac{\mathrm{d} \delta_{12}}{\mathrm{~d} t}+K_{S} \Delta \delta_{12}=-\Delta P_{D C}
$$

where $D$ is the damping coefficient.

By substituting Equation (8) into Equation (10), the following result can be obtained:

$$
M \Delta \frac{d P_{12}^{2}}{d t^{2}}+D \Delta \frac{\mathrm{d} P_{12}}{\mathrm{~d} t}+K_{S} \Delta P_{12}=-K_{S} \Delta P_{D C}
$$

From the above, by the rotor equation of the equivalent generators and single-machine form, the AC tie-line power can be expressed as a second-order linear system with equivalent DC transmission power drop in two-area AC/DC parallel interconnected power system.

\section{Analysis of the Power Fluctuations in an AC System Caused by DC Faults}

In a two-area AC/DC parallel interconnected power system, DC faults cause a DC power loss that may lead to power oscillations in AC systems. If the fluctuation amplitude is large enough, the stability of a power system may be threatened. In this section, based on the power system three-stage power allocation theory after power impacts, the power fluctuation mechanism of an AC system caused by DC faults is analyzed, and the factors affecting the power angle stability of this AC system are described.

\subsection{Three-Stage Power Allocation Theory after a Power Imapct}

After power is impacted at the disturbance point, the generation will be readjusted to achieve a new balance between generation and load power. This dynamic process is generally divided into three stages [44].

The first stage is the disturbance moment. The variation of the generator output power is distributed according to the synchronous torque coefficient between the generator and the disturbance point. The shorter the electrical distance is to the disturbance point, the smaller the initial angle difference will be, and the greater the disturbance power will be shared by the generator.

The second stage is before the disturbance occurs, and the governor action of the generator causes the mechanical power of the prime mover to change considerably. In this stage, due to the sudden increase or decrease of the electromagnetic power, the generator will be decelerated or accelerated, respectively. If the transient process time is long enough, the generator can obtain the average system acceleration. Furthermore, the governor has not yet caused a significant change in the mechanical power of the prime mover in this process, and the generator shares the load only according to its inertia constant.

In the third stage, the frequency fluctuation of the system tends to be stable, and the generator changes the prime mover output power through the governor response, which then changes the generator output power. In this stage, the disturbance power is distributed to each generator according to the governor adjustment system.

\subsection{Analysis of the Unit Impulse Response of a Second-Order System}

The standard form of the transfer function for second-order linear systems is [45]: 


$$
G(s)=\frac{\omega_{n}^{2}}{s^{2}+2 \xi \omega_{n} s+\omega_{n}^{2}}
$$

where $\omega_{n}$ and $\xi$ denote the natural oscillation frequency and damping coefficient of system, respectively. The characteristic equation of a second order system is:

$$
s^{2}+2 \xi \omega_{n} s+\omega_{n}^{2}=0
$$

The characteristic root can be expressed as:

$$
S_{1,2}=-\xi \omega_{n} \pm \omega_{n} \sqrt{\xi^{2}-1}
$$

From Equation (12), the unit impulse response of a second-order system can be obtained as follows:

$$
x_{0}(t)=\mathcal{L}^{-1}\left[\frac{\omega_{n}^{2}}{\left(s+\xi \omega_{n}\right)^{2}+\left(\omega_{n} \sqrt{\xi^{2}-1}\right)^{2}}\right]
$$

where the characteristic roots and dynamic responses vary with the values of $\xi$.

When $0<\xi<1$,

$$
x_{0}(t)=\frac{\omega_{n}}{\sqrt{1-\xi^{2}}} e^{-\xi \omega_{n} t} \sin \omega_{n} \sqrt{1-\xi^{2}} t, t \geq 0
$$

\subsection{The Power Oscillation Mechanism of an AC System Caused by CFS}

After a DC CF occurs, the first peak of the power oscillation after fault has the most serious impact on the AC tie-lines, and the power loss due to a CF cannot simply be replaced by a square wave. In addition, when the power fluctuation reaches the peak value of the first oscillation, the governor usually does not cause a significant change in the mechanical power of the prime mover. The influence of the generator power regulation can be neglected when calculating the first oscillation peak of the system power. That is, only the first two stages of power allocation mentioned in Section 3.1 are considered.

The oscillation modes of two-area power grids transmitted in parallel by AC and DC are studied in this paper. It can be considered that the units in the two $\mathrm{AC}$ regional power grids are coordinated. According to Equation (11), from the small disturbance dynamic stability analysis theory of power systems, the model with only generator rotor angle variables can be written as a second-order linear system model, as mentioned in Section 3.2.

When $0<\xi<1$, we get Equation (16), and derivative of $t$, order $\frac{d y}{d t}=0$, the first swing peak time of the unit impulse response is obtained as follows:

$$
t_{P}=\beta / \omega_{d}
$$

where $\omega_{d}=\omega_{n} \sqrt{1-\xi^{2}}$ denotes the oscillation frequency, and $\beta=\tan ^{-1}\left(\frac{\sqrt{1-\xi^{2}}}{\xi}\right)$. The impulse response peak value is:

$$
y\left(t_{P}\right)=\omega_{n} e^{-\beta / \tan \beta}
$$

It can be seen that the peak value and the time of the first oscillation of the unit impulse response curve of the second-order linear system are mainly determined by the natural oscillation frequency and the damping ratio of the system.

For an AC/DC parallel transmission system, CFs are quite a complex dynamic process that involve various levels of control. However, the duration of CFs (tens to hundreds of milliseconds) is very short compared with the power oscillation period (several seconds) of AC tie-line in general, thus, the power 
oscillation during CFs can be regarded as the impact on the system. The effect of DC energy loss during $\mathrm{CFs}$ is concerned. From the perspective of energy, the DC power loss by CFs can be expressed as:

$$
\Delta P_{D C}(t)=\Delta E_{D C} \cdot d(t)
$$

where $d(t)$ is the unit impulse function and $\Delta E_{D C}$ is impact amplitude coefficient, that is, the energy loss during a CF. For the case of multiple CFs occurring at the same time, it can be expressed as:

$$
\Delta E_{D C}=\sum_{i=1}^{n} \int_{0}^{t_{c i}}\left[P_{D C i}(t)-P_{D C 0 i}\right] d t
$$

where $t_{c i}$ is the $C F$ duration and $P_{D C 0 i}$ and $P_{D C i}$ indicate the initial power and the power during CF of the DC line $i$, respectively. The equivalent $C F$ duration of DC line can be defined as ' $\tau$ ':

$$
\tau=\left\{\sum_{i=1}^{n} \int_{0}^{t_{c i}}\left[P_{D C i}(t)-P_{D C 0 i}\right] d t\right\} /\left(-\sum_{i=1}^{n} P_{D C 0 i}\right)
$$

This means that:

$$
\Delta E_{D C}=-\sum_{i=1}^{n} P_{D C 0 i} \tau
$$

Through Equations (19)-(22), the DC energy loss caused by CFs is expressed by the initial DC operation power and the equivalent commutation failure time.

From Equation (16), the power wave equation of the system after a CF impact is as follows:

$$
\Delta P_{12}(t)=-\frac{\Delta E_{D C} \omega_{n} e^{-\xi \omega_{n} t}}{\sqrt{1-\xi^{2}}} \sin \left(\omega_{n} \sqrt{1-\xi^{2}} t\right)
$$

where $\omega_{n}=\sqrt{\frac{K_{s}}{M}}, \xi=\frac{D}{2 \sqrt{K_{s} M}}$.

In this paper, from Equation (22), the power wave equation can be expressed as:

$$
\Delta P_{12}(t)=-\frac{\Delta P_{D C} \tau \omega_{n} e^{-\xi \omega_{n} t}}{\sqrt{1-\xi^{2}}} \sin \left(\omega_{n} \sqrt{1-\xi^{2} t}\right)
$$

For an actual power system, the value of the damping ratio of a regional oscillation mode $\xi$ is $\ll 1$, and from $\beta=\tan ^{-1}\left(\frac{\sqrt{1-\xi^{2}}}{\xi}\right)$, it is determined that: $\beta \approx \frac{\pi}{2}$ and $\tan \beta \approx \frac{1}{\xi}$, which is substituted into Equations (17) and (24). Thus, the first swing peak of the equivalent power fluctuation of an AC system caused by a CF is as follows:

$$
\begin{gathered}
t_{P}=\pi / 2 \omega_{d} \\
\Delta P_{D C}\left(t_{P}\right)=\Delta P_{D C} \tau \omega_{n} e^{-\xi \pi / 2}
\end{gathered}
$$

In summary, the key factors of the power fluctuation amplitude of an $\mathrm{AC}$ system after a $\mathrm{CF}$ include the power drop amplitude, the equivalent commutation time, the oscillation frequency and the damping ratio of the oscillation mode in the system area, and the peak time is mainly determined by the oscillation frequency.

The key factors influencing the peak value of the AC tie-line power oscillation include the DC power and the equivalent $\mathrm{CF}$ duration, the frequency and damping ratio of dominant area oscillation mode. The peak time is mainly determined by the oscillation frequency. 


\section{Simulation and Analysis}

In order to verify the accuracy of the proposed theory, an extended IEEE-39-bus AC/DC parallel interconnected power system is built. The topological structure is shown in Figure 3. The simulation tool is advanced digital power system simulator (ADPSS) that is developed by the China Electric Power Research Institute. The extended IEEE-39-bus systems are used to simulate the sending and receiving power grids separately. The two areas are connected by AC/DC parallel transmission system. For the DC transmission line, the control strategy is used a constant current controller on the at rectifier side and a constant arc extinguishing angle controller on the at inverter side.

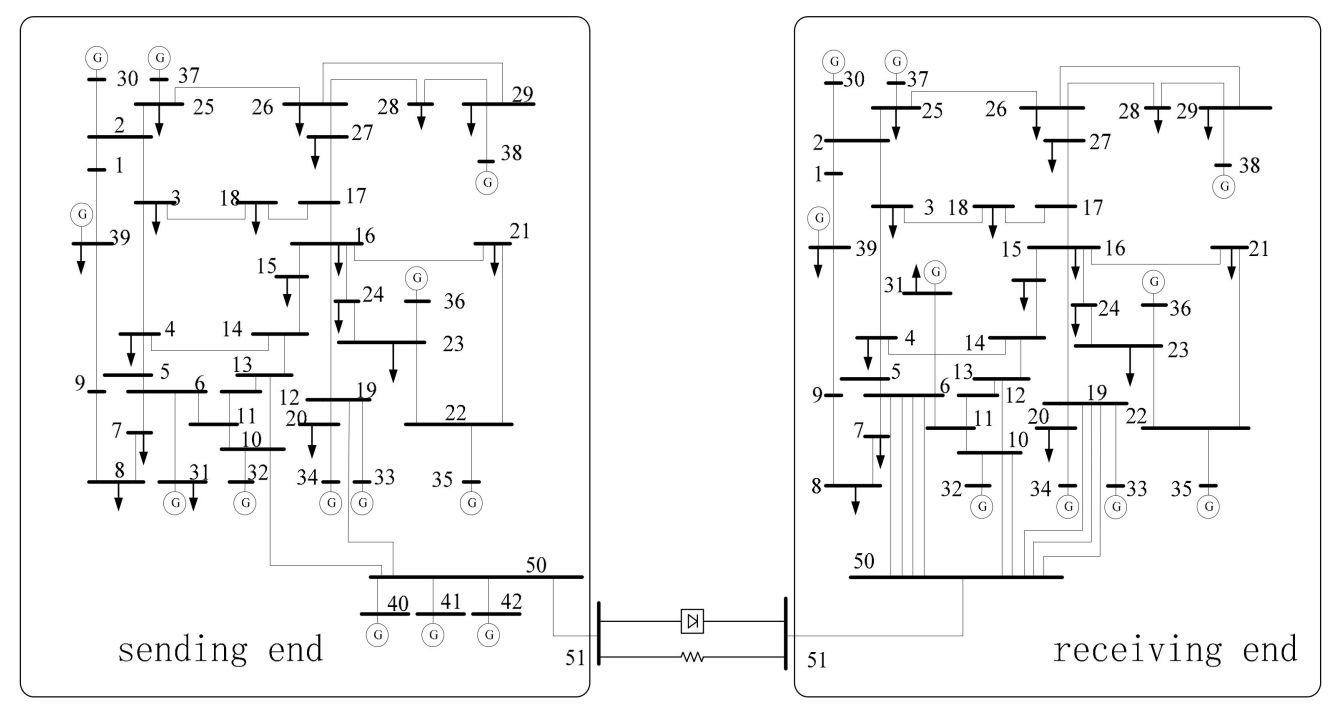

Figure 3. The topological structure of the two-area IEEE-39 AC/DC parallel interconnected power system.

For both ends of the AC system, the relative angle between the generators is not changed during the transient process (their absolute angle variations are similar). These generators are called coherent generator groups. The equivalent inertia time constant could be expressed as:

$$
M_{\Sigma}=M_{1} \frac{S_{1}}{S_{B}}+M_{2} \frac{S_{2}}{S_{B}}+\cdots+M_{n} \frac{S_{n}}{S_{B}}
$$

where $M_{1}, M_{2}, \cdots, M_{n}$ indicate the inertia time constants of each generator separately. $S_{1}, S_{2}, \cdots, S_{n}$ indicate the rated power of each generator separately. $S_{B}$ indicates the power reference value. In this model, the total inertia constants of the two area power systems are equal to $29.396 \mathrm{~s}$.

In addition, the static reserve coefficient of the equivalent system can be expressed as:

$$
K_{P}=\frac{P_{E \max }^{\prime}-\left(P_{12}^{\prime}+P_{D C}^{\prime}\right)}{P_{12}^{\prime}+P_{D C}^{\prime}} \times 100 \%
$$

According to the Current Guidelines for Power System Safety and Stability in China, in the normal operating mode, the static reserve coefficient $K_{P}$ should be in the range of $15-20 \%$. Thus, to ensure the system satisfies the static stability range, $\delta_{12}$ may be equal to $56^{\circ}-61^{\circ}$. Using the following three examples, the correctness and effectiveness of the algorithms were verified, and the influence of the peak value of the power oscillation of an AC tie-line for a two-area AC/DC parallel interconnected power system is explained. 
4.1. Simulation and Verification of the Peak Value of an AC Tie-Line Power Oscillation on a Two-Area AC/DC Parallel Interconnected Power System

In the simulation system, the maximum transmission capacity of the AC tie-line is 7.5 p.u. To analyze the influence of large capacity DC CFs on the parallel AC tie-line, the DC transmission power is assumed to be $P_{D C}=10$ p.u. To ensure that the transmission system can make full use of the power stable transmission capacity of the AC tie-line under the condition of static stability reserve, the stable operating power angle of the AC tie-line is set to a value of $\delta_{120}=60.2^{\circ}$, and the transmission power is $P_{12}=6.54$ p.u. After the system is operating in a stable state, a CF is occurred in the DC transmission line at $20 \mathrm{~s}$. The transmission power of the DC line is shown in Figure 4 . The fault caused an instantaneous power surplus at the sending end of the AC system that impacts the AC tie-line. The simulation results show that the peak value of the power oscillation of the AC tie-line is 6.6648 p.u., and using the method presented in this paper, the peak value of the AC tie-line power oscillation is calculated to be 6.77 p.u. The relative error of the two methods is $1.64 \%$. Furthermore, to study the influence of a DC commutation failure on different power fluctuations of AC tie lines, the AC tie-line transmission power is changed, which is reflected in a change of the phase angle between the buses of the AC tie-line. The simulation curves are shown in Figure 5. In addition, the frequencies and damping ratios of the dominant area oscillation mode, the equivalent commutation times, the peak values of the power oscillation of the AC tie-line and the relative errors are listed in Table 1.

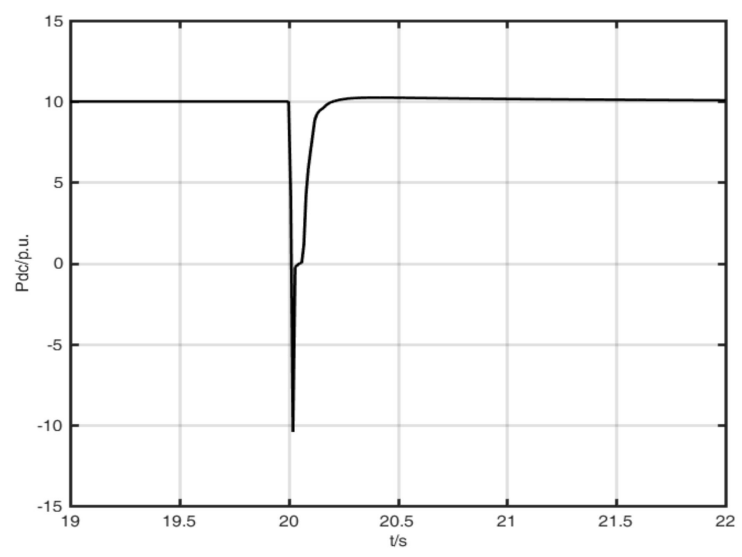

Figure 4. Transmission power of the DC line.

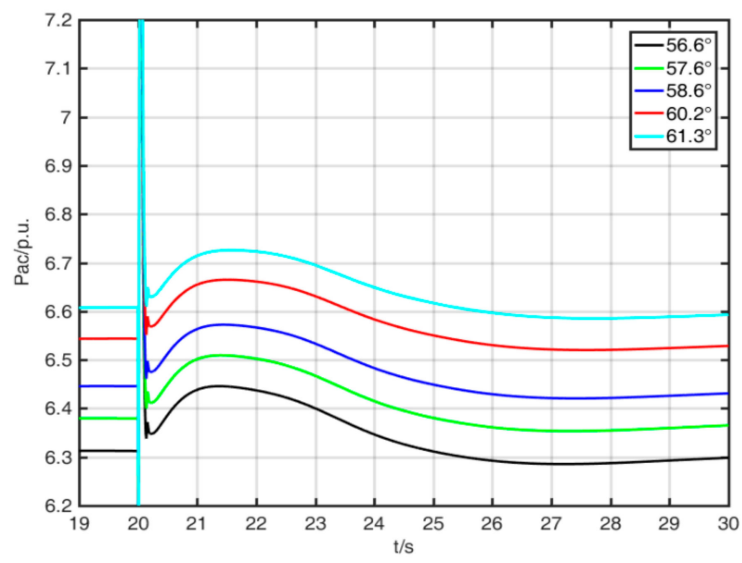

Figure 5. Power oscillation of AC tie-line at different stable operating power angles $\left(P_{D C}=10\right.$ p.u. $)$.

The results show that with increasing power angle at the operating point, the oscillation frequency of the regional oscillation mode is decreased, the damping ratio is increased, the failure time of DC equivalent commutation is increased, and the peak value of AC tie-line power oscillations is increased. Comparing the simulation results with the calculated results of the method proposed in this paper, the 
relative errors are less than $2 \%$. The error is mainly caused by the system equivalence and linearization in the derivation of the equation, but the results can meet the engineering requirements.

Table 1. Parameters affecting the power oscillation of AC tie-line.

\begin{tabular}{|c|c|c|c|c|c|c|}
\hline \multirow{2}{*}{$\begin{array}{l}\text { Equilibrium } \\
\text { Point }\left(\delta_{120}\right)\end{array}$} & \multirow{2}{*}{$\begin{array}{c}\text { Natural } \\
\text { Oscillation } \\
\text { Frequency } \\
\left(\omega_{n} / \mathrm{rad}\right)\end{array}$} & \multirow{2}{*}{$\begin{array}{c}\text { Damping } \\
\text { Coefficient } \\
(\xi / \%)\end{array}$} & \multirow{2}{*}{$\begin{array}{l}\text { Equivalent } \\
\text { CF Duration } \\
(\tau / \mathrm{s})\end{array}$} & \multicolumn{3}{|c|}{$\begin{array}{c}\text { Peak Value of the Power Oscillation of } \\
\text { AC Tie-Line }\end{array}$} \\
\hline & & & & $\begin{array}{l}\text { Simulation } \\
\text { Results/p.u. }\end{array}$ & $\begin{array}{l}\text { Calculation } \\
\text { Results/p.u. }\end{array}$ & $\begin{array}{l}\text { Relative } \\
\text { Error/\% }\end{array}$ \\
\hline $56.6^{\circ}$ & 0.3676 & 0.463 & 0.0667 & 6.4456 & 6.5557 & 1.71 \\
\hline $57.6^{\circ}$ & 0.3622 & 0.470 & 0.0667 & 6.5093 & 6.6191 & 1.69 \\
\hline $58.6^{\circ}$ & 0.3568 & 0.477 & 0.0667 & 6.5722 & 6.6817 & 1.67 \\
\hline $60.2^{\circ}$ & 0.3483 & 0.489 & 0.0667 & 6.6648 & 6.7739 & 1.64 \\
\hline $61.3^{\circ}$ & 0.3418 & 0.498 & 0.0667 & 6.7254 & 6.8338 & 1.61 \\
\hline
\end{tabular}

\subsection{Influence of a DC Power Loss on the Peak Value of the Oscillations of the AC Tie-Line}

The DC power transmission power is changed to $P_{D C}=8$ p.u., and the power of the AC tie-line is kept the same as that of Section 4.1. When a CF is occurred, the AC tie-line power fluctuations are occurred at different operating points, as shown in Figure 6. Under the different DC power loss conditions, the power fluctuation curves of the AC tie-line at the same operating point are shown in Figure 7, and the simulation and calculation results of the peak power oscillation of AC tie-line are listed in the Table 2. It could be seen that the peak values of the power oscillations are increased with the increase of DC power. In addition, under the condition of guaranteeing system static stability range and with the increase of power angle of AC tie-line, the calculation results of the peak value of power oscillations are closer to the simulation value. Thus, in this region, the linear effect is better.

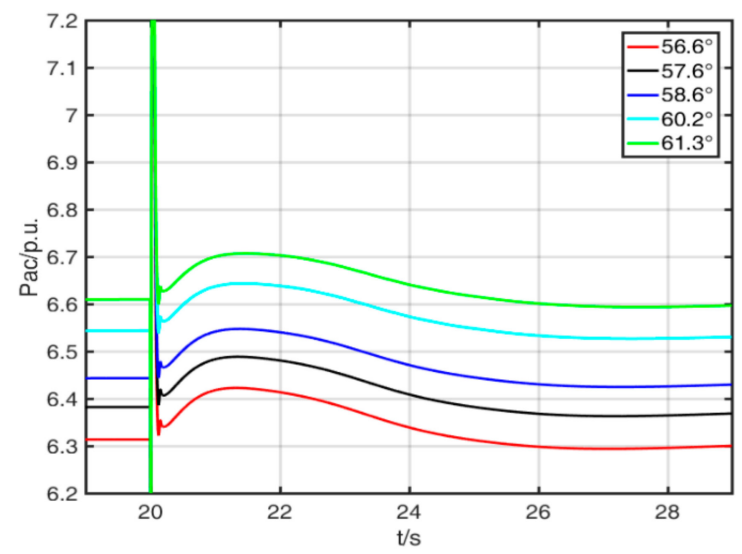

Figure 6. Power oscillations of the AC tie-line at different stable operating power angles $\left(P_{D C}=8\right.$ p.u. $)$.

Table 2. Simulation and calculation results of the peak power oscillations of the AC tie-line.

\begin{tabular}{ccccc}
\hline \multirow{2}{*}{$\begin{array}{c}\text { Equilibrium } \\
\text { Point }\left(\delta_{\mathbf{1 2 0}}\right)\end{array}$} & \multicolumn{2}{c}{$\begin{array}{c}\text { Peak Power of AC Tie-Line } \\
\left(\boldsymbol{P}_{\boldsymbol{D C}}=\mathbf{8 0 0} \mathbf{M W}\right)\end{array}$} & \multicolumn{2}{c}{$\begin{array}{r}\text { Peak Power of AC Tie-Line } \\
\left(\boldsymbol{P}_{\boldsymbol{D C}}=\mathbf{1 0 0 0} \mathbf{M W}\right)\end{array}$} \\
\cline { 2 - 5 } & $\begin{array}{c}\text { Simulation } \\
\text { Results/p.u. }\end{array}$ & $\begin{array}{c}\text { Calculation } \\
\text { Results/p.u. }\end{array}$ & $\begin{array}{c}\text { Simulation } \\
\text { Results/p.u. }\end{array}$ & $\begin{array}{c}\text { Calculation } \\
\text { Results/p.u. }\end{array}$ \\
\hline $56.6^{\circ}$ & 6.4223 & 6.5098 & 6.4456 & 6.5557 \\
$57.6^{\circ}$ & 6.4883 & 6.5755 & 6.5093 & 6.6191 \\
$58.6^{\circ}$ & 6.5470 & 6.6337 & 6.5722 & 6.6817 \\
$60.2^{\circ}$ & 6.6434 & 6.7296 & 6.6648 & 6.7739 \\
$61.3^{\circ}$ & 6.7068 & 6.7924 & 6.7254 & 6.8338 \\
\hline
\end{tabular}




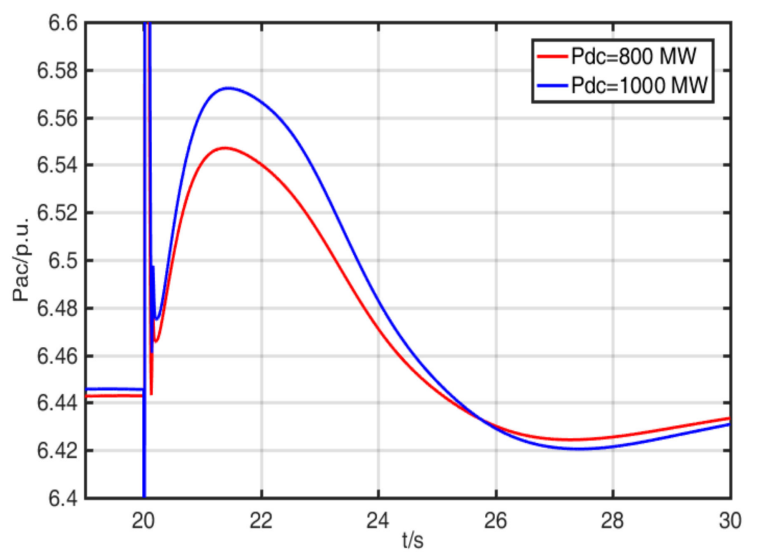

Figure 7. Power oscillations of the AC tie-line at the same stable operating power angle $\left(\delta_{120}=58 \cdot 6^{\circ}\right)$.

4.3. Influence of the Frequency and Damping Ratio of the Dominant Area Oscillation Mode on the Peak Value of the Power Oscillations of the AC Tie-Line

In the model of Section 4.1, the type of transmission line is changed such that the DC transmission power is $P_{D C}=10 \mathrm{p} . u$. and the stable operating power angle of the AC tie-line is $\delta_{120}=60.2^{\circ}$. After the system operating in a stable state, a CF is occurred in the DC transmission line at $20 \mathrm{~s}$. The results of AC tie-line power oscillations are shown in Figure 8. The conductor type and reactance of the AC tie-line, the frequencies and damping ratios of the dominant area oscillation modes, the equivalent $\mathrm{CF}$ duration and the simulation and calculation results of the peak power oscillations of the AC line are listed in Table 3. It could be seen that, with the decrease of the reactance of the AC tie-line, the natural oscillation frequency is decreased, the damping coefficient is increased, the equivalent CF duration is increased, and the peak value of the power oscillations is increased.

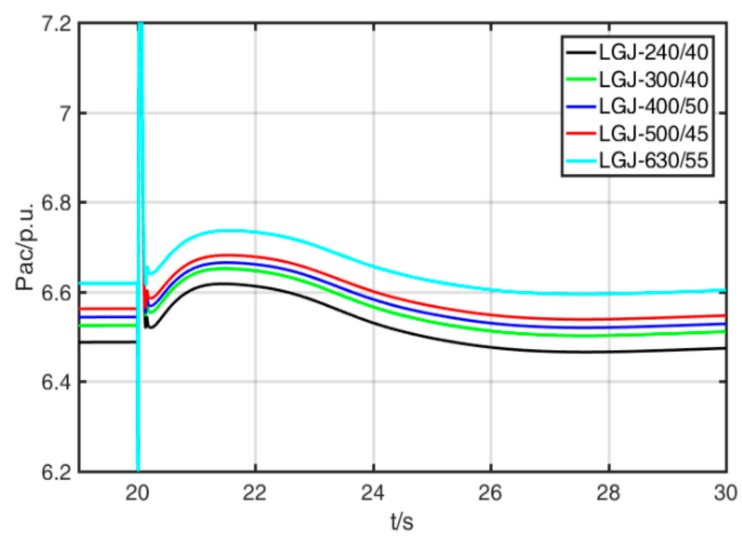

Figure 8. Power oscillations of the AC tie-line with different types of transmission lines.

Table 3. Parameters affecting the power oscillations of different types of transmission lines.

\begin{tabular}{|c|c|c|c|c|c|c|}
\hline \multirow{2}{*}{$\begin{array}{c}\text { Conductor } \\
\text { Type of AC } \\
\text { Tie-Line }\end{array}$} & \multirow{2}{*}{$\begin{array}{c}\text { Reactance } \\
\text { of AC } \\
\text { Tie-Line } \\
\left(x_{12} / \text { p.u. }\right)\end{array}$} & \multirow{2}{*}{$\begin{array}{c}\text { Natural } \\
\text { Oscillation } \\
\text { Frequency } \\
\left(\omega_{n} / \text { rad }\right)\end{array}$} & \multirow{2}{*}{$\begin{array}{c}\text { Damping } \\
\text { Coefficient } \\
(\xi / \%)\end{array}$} & \multirow{2}{*}{$\begin{array}{c}\text { Equivalent } \\
\text { CF Duration } \\
(\tau / s)\end{array}$} & \multicolumn{2}{|c|}{$\begin{array}{l}\text { Peak Value of the Power } \\
\text { Oscillation of AC Tie-Line }\end{array}$} \\
\hline & & & & & $\begin{array}{l}\text { Simulation } \\
\text { Results/p.u. }\end{array}$ & $\begin{array}{l}\text { Calculation } \\
\text { Results/p.u. }\end{array}$ \\
\hline LGJ-240/40 & 0.1361 & 0.3438 & 0.495 & 0.0667 & 6.6175 & 6.7154 \\
\hline LGJ-300/40 & 0.1344 & 0.3460 & 0.492 & 0.0667 & 6.6513 & 6.7541 \\
\hline LGJ-400/50 & 0.1327 & 0.3483 & 0.489 & 0.0667 & 6.6648 & 6.7739 \\
\hline LGJ-500/45 & 0.1315 & 0.3497 & 0.486 & 0.0667 & 6.6812 & 6.7935 \\
\hline LGJ-630/55 & 0.1294 & 0.3525 & 0.483 & 0.0666 & 6.7359 & 6.8518 \\
\hline
\end{tabular}




\section{Conclusions}

In this paper, the peak values of the AC tie-line power oscillations on a two-area AC/DC parallel interconnected power system caused by HVDC commutation failures are studied. Because the duration of a DC commutation failure is very short compared with the power oscillation period of an AC tie-line, the power fluctuations during a DC commutation failure can be regarded as the impulse response model of second-order linear system. Based on this, the mechanism of power oscillation on the AC tie-line caused by CF was clarified. The key factors influencing the peak value of the AC tie-line power oscillation are proved to be the DC power and the equivalent CF duration, the frequency and damping ratio of the dominant area oscillation mode. Meanwhile, the peak time is mainly determined by the oscillation frequency. Finally, the correctness and effectiveness of the algorithms were verified by a simulation analysis of an extended IEEE-39-bus AC/DC parallel interconnected power system. These research results are helpful for understanding the dynamic characteristics of AC tie-line power fluctuations in an AC/DC parallel transmission system. It can provide a basis for the arrangement of the operating modes and the formulation of control measures for interconnected power grids. In addition, the control measures for reducing the large power oscillations after a power disturbance and improving the stability of an AC/DC parallel interconnected power system in a UHV power grid are important works in the future.

Author Contributions: L.S. designed the research and wrote the paper; C.M. performed the experiment; H.L. provided professional guidance; L.S. and C.M. reviewed the paper. All authors have read and agreed to the published version of the manuscript.

Funding: This work was supported by the National Key Research and Development Program of China (2017YFB0902000).

Conflicts of Interest: The authors declare no conflict of interest.

\section{Nomenclature}

$\begin{array}{ll}E_{1}, E_{2} & \text { Equivalent internal potential of the sending and receiving ends } \\ \delta_{1}, \delta_{2} & \text { Equivalent rotor angle of sending and receiving ends } \\ U_{1}, U_{2} & \text { Bus voltage of sending and receiving ends } \\ \theta_{1}, \theta_{2} & \text { Phrase angle of sending and receiving ends } \\ x_{1}, x_{2} & \text { Equivalent transmission line reactance values } \\ x_{12} & \text { AC tie-line reactance interconnecting the sending and receiving ends } \\ P_{G 1}, P_{G 2} & \text { Equivalent generator mechanical power values } \\ P_{L 1}, P_{L 2} & \text { Equivalent load power of sending and receiving ends } \\ P_{12} & \text { Equivalent AC tie-line power interconnecting sending and receiving end } \\ P_{D C} & \text { Equivalent DC transmission power } \\ M_{1}, M_{2} & \text { Equivalent generator inertia of sending and receiving ends } \\ K_{S} & \text { Synchronous torque coefficient of the AC tie-line } \\ D & \text { Damping coefficient } \\ \delta_{12} & \text { Equivalent rotor angle difference between the sending and receiving end } \\ \delta_{120} & \text { Equivalent rotor angle of the AC tie-line equilibrium point } \\ \omega_{n} & \text { Natural oscillation frequency } \\ \xi & \text { Damping coefficient }\end{array}$

\section{References}

1. Miao, Y.C.; Cheng, H.Z. An optimal reactive power control strategy for UHVAC/DC hybrid system in east China grid. IEEE Trans. Smart Grid. 2016, 7, 392-399. [CrossRef]

2. Sun, J.; Li, M.J.; Zhang, Z.G.; Xu, T.; He, J.B.; Wang, H.J.; Li, G.H. Renewable energy transmission by HVDC across the continent: System challenges and opportunities. CSEE JPES. 2017, 4, 353-364. [CrossRef]

3. Jiang, Y.Y.; Chen, X.L.; Peng, S.; Du, X.; Xu, D.; Tang, J.J.; Li, W.Y. Study on emergency load shedding of hybrid $\mathrm{AC} / \mathrm{DC}$ receiving-end power grid with stochastic, static characteristics-dependent load model. Energies 2019, 12, 3912. [CrossRef] 
4. Shu, Y.B.; Chen, G.P.; Yu, Z.; Zhang, J.Y.; Wang, C.; Zheng, C. Characteristic analysis of UHVAC/DC hybrid power grids and construction of power system protection. CSEE JPES. 2017, 3, 325-334. [CrossRef]

5. Li, Y.L.; Sun, Q.H.; Chen, G.P.; Li, M.J.; Xu, T.; Yu, Z.; He, J.B.; Li, B.Q.; Guo, Q.; Zhu, Y.Y.; et al. New generation UHVAC/DC power grid simulation platform architecture. In Proceedings of the 2018 International Conference on Power System Technology (POWERCON), Guangzhou, China, 6-8 November 2018; pp. 115-122.

6. Liao, S.W.; Yao, W.; Ai, X.M.; Wen, J.Y.; Liu, Q.; Jiang, Y.H.; Zhang, J.; Tu, J.Z. An improved multi-infeed effective short-circuit ratio for AC/DC power systems with massive shunt capacitors installed. Energies 2017, 10, 396. [CrossRef]

7. Arif, M.; Ahmad, F.; Kashyap, R.; Abdel-Galil, T.K.; Othman, M.M.; EI-Amin, I.; AI-Mubarak, A. Evaluation of EHV and AC/DC technologies for integration of large-scale renewable generation in Saudi Arabian network. IET Gener. Transm. Distrib. 2019, 13, 575-581. [CrossRef]

8. Cheng, R.; Xu, Z.F.; Liu, P.; Wang, Z.; Li, Z.; Jones, I. A multi-region optimization planning model for China's power sector. Appl. Energy 2015, 137, 413-426. [CrossRef]

9. Hao, M.Z.; Wang, Q.; Li, Y.Q.; Luo, Y.Z.; Jia, L.; Zi, P.; Song, Y.T.; Zhao, D.M. Difference analysis of AC tie-line power fluctuation caused by different DC blocking for two-area interconnected power systems. In Proceedings of the 2017 IEEE Conference on Energy Internet and Energy System Integration (EI2), Beijing, China, 26-28 November 2018; pp. 1-5.

10. Zhao, W.W.; Xiao, B.; Zhang, Z.X.; Liang, P. Study on the mechanism of AC tie-line power fluctuation for a two-area interconnected power system. In Proceedings of the 2017 IEEE PES Innovative Smart Grid Technologies Conference Europe (ISGT-Europe), Torino, Italy, 26-29 September 2017; pp. 1-6.

11. Chen, L.; Nian, H.; Xu, Y.Y. Impedance aggregation method of multiple wind turbines and accuracy analysis. Energies 2019, 12, 2035. [CrossRef]

12. An, T.; Han, C.D.; Wu, Y.N.; Tang, G.F. HVDC grid test models for different application scenarios and load flow studies. Mod. Power Syst. Clean Energy 2017, 5, 262-274. [CrossRef]

13. Zhang, F.; Xin, H.H.; Wu, D.; Wang, Z.; Gan, D.Q. Assessing strength of multi-infeed LCC-HVDC systems using generalized short-circuit ratio. IEEE Trans. Power Syst. 2019, 34, 467-480. [CrossRef]

14. Xiao, H.; Li, Y.H.; Shi, D.Y.; Chen, J.F.; Duan, X.Z. Evaluation of strength measure for static voltage stability analysis of hybrid multi-infeed DC systems. IEEE Trans. Power Deliv. 2019, 30, 737-745. [CrossRef]

15. Bidadfa, A.; Nee, H.P.; Zhang, L.D.; Harnefors, L.; Namaayantavana, S.; Karrari, M.; Gharephetian, G.B. Power system stability analysis using feedback control system modeling including HVDC transmission links. IEEE Trans. Power Syst. 2016, 31, 116-124. [CrossRef]

16. Wang, L.; Thi, M.S. Stability enhancement of large-scale integration of wind, solar, and marine-current power generation fed to an SG-based power system through an LCC-HVDC link. IEEE Trans. Sustain Energy 2014, 5, 160-170. [CrossRef]

17. Azad, S.P.; Iravani, R.; Tate, J.E. Stability enhancement of a DC-segmented AC power system. IEEE Trans. Power Deliv. 2015, 30, 737-745. [CrossRef]

18. Liu, M.; Zheng, L.; Shi, F.F.; Li, K. Commutation failure caused by AC filter switching In HVDC system. J. Eng. 2019, 2019, 889-892. [CrossRef]

19. Arrillaga, J. Static power conversion. In High Voltage Direct Current Transmission, 2nd ed.; The Institution of Engineering and Technology: London, UK, 1998; Volume 6, pp. 10-23.

20. Tang, Y.; Zheng, C.Y. Review on influencing factors of commutation failure in HVDC systems. Proc. CSEE 2019, 39, 499-513. (In Chinese)

21. Li, G.Q.; Zhang, S.; Jiang, T.; Chen, H.H.; Li, X. A method of detecting commutation failure in multi-infeed HVDC systems based on critical failure impedance boundary. In Proceedings of the 2017 IEEE Power \& Energy Society General Meeting, Chicago, IL, USA, 16-20 July 2017; pp. 1-5.

22. Xiao, C.; Xiong, X.F.; Ouyang, J.X.; Ma, G.T.; Zheng, D.; Tang, T. A commutation failure suppression control method based on the controllable operation region of hybrid dual-infeed HVDC system. Energies 2018, 11, 574. [CrossRef]

23. Sun, Y.Z.; Peng, L.; Ma, F.; Li, G.J.; Lv, P.E. Design a fuzzy controller to minimize the effect of HVDC commutation failure on power system. IEEE Trans. Power Syst. 2008, 23, 100-107. [CrossRef]

24. Bauman, J.; Kazerani, M. Commutation failure reduction in HVDC systems using adaptive fuzzy logic controller. IEEE Trans. Power Syst. 2007, 22, 1995-2002. [CrossRef] 
25. Rahimi, E.; Gole, A.M.; Davies, J.B.; Fernando, I.; Kent, K.L. Commutation failure analysis in multi-infeed HVDC systems. IEEE Trans. Power Deliv. 2011, 26, 378-384. [CrossRef]

26. Son, H.I.; Kim, H.M. An algorithm for effective mitigation of commutation failure in High-Voltage Direct-Current systems. IEEE Trans. Power Deliv. 2016, 31, 1437-1446. [CrossRef]

27. Li, X.N.; Li, F.Q.; Chen, S.Y.; Li, Y.N.; Zou, Q.; Wu, Z.P.; Lin, S.B. An improved commutation prediction algorithm to mitigate commutation failure in high voltage direct current. Energies 2017, 10, 1481. [CrossRef]

28. Misaeidi, S.; Dong, X.Z.; Tzelepis, D.; Said, D.M.; Dysko, A. A predictive control strategy for mitigation of commutation failure in LCC-based HVDC systems. IEEE Trans. Power Electron. 2019, 34, 160-172. [CrossRef]

29. Hu, J.; Wang, J.; Xiong, X.F.; Chen, J. A post-contingency power flow control strategy for AC/DC hybrid power grid considering the dynamic electrothermal effects of transmission lines. IEEE Access 2019, 7, 65288-65302. [CrossRef]

30. Wei, Z.; Yuan, Y.; Lei, X.; Wang, H.; Sun, G.; Sun, Y. Direct-current predictive control strategy for inhibiting commutation failure in HVDC converter. IEEE Trans. Power Syst. 2014, 29, 2409-2417. [CrossRef]

31. Lin, T.; Guo, Z.Y.; Wang, L.Y.; Chen, R.S.; Bi, R.Y. Novel detection method for consecutive DC commutation failure based on daubechies wavelet with 2nd-order vanishing moments. Energies 2018, 11, 261. [CrossRef]

32. Yang, Y.Y.; Zhang, P.J. Study on the influence of inconsistent valve parameters on LCC-HVDC commutation and operation. IEEE Access 2019, 7, 109015-109025. [CrossRef]

33. Xue, Y.; Zhang, X.P.; Yang, C.H. Elimination of commutation failures of LCC HVDC system with controllable capacitors. IEEE Trans. Power Syst. 2016, 31, 3289-3299. [CrossRef]

34. Xue, Y.; Zhang, X.P. Reactive power and AC voltage control of LCC HVDC system with controllable capacitors. IEEE Trans. Power Syst. 2017, 32, 753-764. [CrossRef]

35. Xue, Y.; Zhang, X.P.; Yang, C.H. AC filterless flexible LCC HVDC with reduced voltage rating of controllable capacitors. IEEE Trans. Power Syst. 2018, 33, 5507-5518. [CrossRef]

36. Ni, X.J.; Zhao, C.Y.; Guo, C.Y.; Liu, H.; Liu, Y.C. Enhanced line commutated converter with embedded fully controlled sub-modules to mitigate commutation failures in high voltage direct current systems. IET Power Electron. 2016, 9, 198-206. [CrossRef]

37. Paspatis, A.G.; Konstatopoulos, G.C. Voltage support under grid faults with inherent current limitation for three-phase droop-controlled inverters. Energies 2019, 12, 997. [CrossRef]

38. Sha, J.B.; Guo, C.Y.; Rehman, A.U.; Zhao, C.Y. A Quantitative index to evaluate the commutation failure probability of LCC-HVDC with a synchronous condenser. Appl. Sci. 2019, 9, 925. [CrossRef]

39. Paulino, J.O.S.; Barbosa, C.F.; Lopes, I.J.S.; Boaventura, W.D.C. An approximate formula for the peak value of lightning-induced voltages in overhead lines. IEEE Trans. Power Syst. 2010, 25, 843-851. [CrossRef]

40. Zhang, Q.L.; Zhang, L.; Tang, X.; Gao, J.G. An approximate formula for estimating the peak value of lightning-induced overvoltage considering the stratified conducting ground. IEEE Trans. Power Deliv. 2014, 29, 884-889. [CrossRef]

41. Zhao, W.; Tehranipoor, M. Peak power identification on power bumps during test application. In Proceedings of the 2011 International Green Computing Conference and Workshops, Orlando, FL, USA, 25-28 July 2011; pp. $1-3$.

42. He, J.; Tang, Y.; Zhang, J.; Guo, Q.; Yi, J.; Bu, G.Q. Fast calculation of power oscillation peak value on AC tie-line after HVDC commutation failure. IEEE Trans. Power Syst. 2015, 30, 2194-2195. [CrossRef]

43. Ni, Y.X.; Chen, S.S.; Zhang, B.L. The Theory and Analysis of Dynamic Power System; Tsinghua University Press: Beijing, China, 2002; pp. 487-489. (In Chinese)

44. Yi, J.; Tu, J.Z.; Xu, S.Y.; Lin, W.F.; Zhang, J.; Liu, M.S. AC tie-line power fluctuation mechanism and peak value estimation after repeated power impacts in two-area interconnected power systems. Proc. CSEE 2015, 35, 52-58. (In Chinese)

45. Yang, Z.H. Automatic Control Principle; Metallurgical Industry Press: Beijing, China, 1998; pp. $62-73$. (In Chinese)

(C) 2020 by the authors. Licensee MDPI, Basel, Switzerland. This article is an open access article distributed under the terms and conditions of the Creative Commons Attribution (CC BY) license (http://creativecommons.org/licenses/by/4.0/). 